\title{
RANCANG BANGUN SISTEM PAKAR DIAGNOSIS PENYAKIT MATA DENGAN METODE TEOREMA BAYES
}

\author{
Indra Wahyu Priyana ${ }^{1}$, Diema Hernyka Satyareni ${ }^{2}$ dan Erliyah Nurul Jannah ${ }^{3}$ \\ 1,2,3 Prodi Sistem Informasi, Fakultas Teknik, Universitas Pesantren Tinggi Darul 'Ulum Jombang \\ Jombang, 61481, Indonesia \\ jjgledek0@gmail.com, ${ }^{2}$ diema hs@yahoo.com, ${ }^{3}$ erliyah.nj@gmail.com
}

\begin{abstract}
Abstrak
Penyakit mata merupakan salah satu penyakit berbahaya dalam kesehatan karena bila tidak ditangani dengan cepat akan berakibat kebutaan. Penyakit mata tersebut dapat didiagnosis melalui gejala yang timbul yang diderita oleh manusia tersebut atau melaui gambaran klinisnya, melalui gejala tersebut dapat dibuat sebuah sistem pakar untuk melakukan diagnosis. Sistem pakar adalah sistem yang berusaha mengadopsi pengetahuan manusia ke komputer yang dibangun untuk menyelesaikan masalah seperti seorang pakar.Sistem pakar yang dibuat dalam melakukan diagnosisnya menggunakan metode Teorema Bayesuntuk menghitung probabilitas terjadinya suatu peristiwa berdasarkan pengaruh yang didapat dari hasil observasi maupun pakar.Sistem pakar diagnosis penyakit mata dibangun berbasis web dengan menggunakan bahasa pemrograman PHP (Hipertext Processing) dan database $M y S q l$ versi 5.5.1. Sistem pakar ini mempunyai fitur dan fungsi diantaranya diagnosis penyakit mata dari pengguna yang sudah mendaftar, melihat hasil diagnosis serta mencetak hasil diagnosis, selain itu pengguna dapat melihat informasi kesehatan mata lainnya. Dari hasil pengujian sistem yang dilakukan oleh pakar, uji sistem ini menunjukan bahwa sistem pakar sudah layak digunakan untuk mendiagnosis pasien penyakit mata dengan titik keakuratan mencapai $63,3 \%$.
\end{abstract}

Kata Kunci: Mata, Sistem pakar, Penyakit mata, Teorema Bayes.

\begin{abstract}
Eye disease is also one of the dangerous diseases in health because if not dealt with quickly will result in blindness. The eye disease can be diagnosed mealui the symptoms suffered by the man or through the clinical picture, the symptoms can be made through an expert system for diagnosis. Expert system is a system that is trying to adopt human knowledge into a computer built to solve problems like an expert. Expert systems are made in performing diagnosis using BayesTheorem to calculate the probability of occurrence of an event based on the effect derived from the observation and experts. Eye disease diagnosis expert system is built using a web-based programming languages PHP (Hipertext Processing) version 5.5.1 and MySQL database. This expert system has features and functions including diagnosis of diseases of the eye of users who have signed up, look at the results of the diagnosis and print the results of diagnosis, other than that the user can see the other eye health information. From the test results performed by an expert system tests show that the system is feasible expert system used to diagnose patients with eye diseases accuracy point reaching $63.3 \%$.
\end{abstract}

Keywords: Eyes, System expert, Eye disease, Bayes Theorem 


\section{Pendahuluan}

Mata adalah sebagai jendela dunia karena salah satu organ tubuh terpenting bagi manusia. Penyakit mata juga salah satu penyakit berbahaya dalam kesehatan karena bila tidak ditangani dengan cepat akan berakibat kebutaan. Terbukti dari survey yang diperoleh pusat data dan informasi kesehatan Republik Indonesia, pada tahun 2013 ditemukan 141.232 yang mengidap kebutaan mata dari 5.282.891 penduduk di Jawa Timur. Penanganan gangguan penglihatan membutuhkan tenaga pakar yaitu dokter spesialis mata, sampai dengan desember 2013 di Jawa Timur jumlah spesialis mata sebanyak 1.455 orang (InfoDatin, 2014).

Sistem pakar menawarkan beberapa solusi untuk membantu seorang pakar dalam memecahkan masalah dalam bidang kesehatan.Sistem pakar merupakan sistem yang dirancang untuk dapat menirukan keahlian seseorang pakar dalam menjawab pertanyaan dan menyelesaikan suatu masalah(Arhami, 2005).Dapat di katakan sebagai sistem komputer yang bertujuan untuk menjawab suatu masalah yang menyangkut bidang keahlian kesehatan tertentu. Tujuan pengembangan sistem pakar sebenarnya bukan untuk menggantikan peran manusia, tetapi untuk mensubsitusikan pengetahuan manusia kedalam bentuk sistem, sehingga dapat digunakan oleh orang banyak (Ongko, 2013).

Oleh karena itu dengan adanya permasalahan diatas, maka diperlukan sebuah sistem pakar untuk mendiagnosis penyakit mata dengan menggunakan metode Teorema Bayes. Dalam penerapan metode ini, seorang pakar akan menggambarkan tingkat keakuratan pakar dan tingkat keakuratan sistemyang didapat dari penderita terhadap gejala penyakit mata, sehingga diperoleh nilai probabilitas untuk perhitungan tingkat keakuratan penyakit mata yang dialami penderita tersebut.Hasil dari sistem pakar ini berupa gejala penyakit mata dan penyakit yang dialami, nilai keakuratandan solusi penanganannya.

\section{Metode Penelitian}

Metodeyang digunakan dalam penelitian ini untuk mendiagnosis penyakit mata menggunakan metode Teorema Bayes. Metode Teorema Bayes dikemukakan oleh seorang pendeta Presbyterian inggris pada tahun 1763 yang bernama Thomas Bayes. Teorema Bayes kemudian disempurnakan oleh Laplace.Teorema Bayes digunakan untuk menghitung probabilitas terjadinya suatu peristiwa berdasarkan pengaruh yang didapat dari hasil observasi. Metode ini disamping memanfaatkan data sampel yang diperoleh dari populasi juga menghitung suatu distribusi awal yang disebut distribusi prior.

Metode Teorema Bayesmemandang paramenter sebagai variable yang menggambarkan pengetahuan awal tentang parameter sebelum pengamatan dilakukan dan dinyatakan dalam suatu distribusi yang disebut dengan distribusi prior. Setelah pengamatan dilakukan, informasi dalam distribusi prior dikombinasikan dengan informasi dengan data sampel melalui Teorema Bayes. Sesuai dengan probabilitas subjektif, bila seseorang mengamati kejadian $E$ dan mempunyai keyakinan bahwa kemungkinan akan muncul, maka probabilitas $E$ disebut probabilitas prior. Setelah ada informasi tambahan bahwa misalnya kejadian $H$ telah muncul, mungkin akan terjadi perubahan terhadap perkiraan semula mengenai kemungkinan $E$ untuk muncul. Probabilitas untukH sekarang adalah probabilitas bersyarat akibat $H$ dan disebut probabilitas posterior. Teorema bayes merupakan mekanisme untuk memperbaharui probabilitas dari prior 
menjadi probabilitas posterior (Marlisa, 2014). Adapun perhitungan Teorema Bayes dapat dilihat pada (1), dan untuk keterangan pada (1) terlihat pada Tabel 1.

$$
\frac{P(H \mid E, e)=P(H \mid E) P(e \mid E, H}{P(e \mid E)}
$$

Tabel 1. Keterangan rumus teoremabayes

\begin{tabular}{ll}
\hline$P(H \mid E, e)$ & $\begin{array}{l}\text { Probabilitas hipotesis } \mathrm{H} \\
\text { benar jika muncul } \\
\text { evidence baru } E \text { dari } \\
\text { evidence lama } e\end{array}$ \\
\hline$P(H \mid E)$ & $\begin{array}{l}\text { Probabilitas hipotesis } \mathrm{H} \\
\text { benar jika diberikan } \\
\text { evidence } E\end{array}$ \\
\hline$P(e \mid$ & $\begin{array}{l}\text { Kaitan atar } e \text { dan } E \text { jika } \\
\text { hipotesis } \mathrm{H} \text { evidence } E\end{array}$ \\
\hline$P(e \mid E)$ & $\begin{array}{l}\text { Kaitan antar } e \text { dan } E \\
\text { tanpa memandang }\end{array}$ \\
& hipotesis apapun \\
\hline$E$ & Evidence baru \\
\hline $\mathrm{E}$ & Evidence lama \\
\hline
\end{tabular}

\section{Hasil Penelitian dan Pembahasan}

Berikut ini adalah hasil pengetahuan yang didapat dari pakar yang terdiri dari gejala penyakit mata terlihat pada Tabel 2 , teori pengambilan bobot pada Tabel 3, daftar penyakit mata pada Tabel 4 .

Tabel 2.Gejala penyakit mata

\begin{tabular}{cl}
\hline Kode & \multicolumn{1}{c}{ Gejala } \\
\hline E1 & Silau \\
E2 & $\begin{array}{l}\text { Lensa mata berubah menjadi } \\
\text { keruh. }\end{array}$ \\
& $\begin{array}{l}\text { Penglihatan kabur pada } \\
\text { E3 }\end{array}$ \\
siang hari. \\
E4 & Penglihatan berkabut. \\
E5 & Mata tidak nyeri atau merah. \\
E6 & Mata perlahan kabur sampai \\
E7 & Manya tampak sinar. \\
E8 & Penglihatan kabur \\
E9 & Keluar air mata \\
E10 & Silau
\end{tabular}

E11 Kelopak mata merah

E12 Mata terasa nyeri

E13 Gatal pada tepi kelopak, dan mata merah

E14 Ada benjolan

E15 Mata merah

E16 Mata tidak kabur

E17 Rasa mengganjal pada mata

E18 Kadang terasa gatal - gatal

E19 Mata berair

E20 Mata kabur perlahan

E21 Mata tidak nyeri

E22 Lapangan pandang

Tabel 3.Teori pengambilanbobot

\begin{tabular}{cc}
\hline Tingkat & Nilai probabilitas \\
\hline Pasti & 1 \\
Cukup pasti & $0.7-0.9$ \\
Hampir pasti & $0.4-0.6$ \\
Kurang pasti & $0.1-0.3$ \\
\hline
\end{tabular}

Tabel 4.Daftar Penyakit Mata

\begin{tabular}{ll}
\hline Kode & Penyakit \\
\hline H1 & Katarak \\
H2 & Keratitis \\
H3 & Hordiolom \\
H4 & Konjungtiva \\
H5 & Glukoma \\
\hline
\end{tabular}

Adapun penerapan probabilitas pada sistem pakar untuk mendiagnosis penyakit mata pada manusia adalah sebagai berikut :Pakar akan menentukan nilai probabilitas untuk masing-masing gejala, terlihat pada Tabel 5. 
Tabel 5.Nilai probabilitas gejala

\begin{tabular}{lc}
\hline \multicolumn{1}{c}{ Gejala } & Bobot \\
\hline Silau & 9 \\
Lensa mata berubah menjadi & \\
keruh. & 9 \\
Penglihatan kabur pada siang & \\
hari. & 7 \\
Penglihatan berkabut. & 9 \\
Mata tidak nyeri atau merah. & 5 \\
Mata perlahan kabur sampai & \\
hanya tampak sinar. & 6 \\
Mata merah & 9 \\
Penglihatan kabur & 5 \\
Keluar air mata & 5 \\
Silau & 6 \\
Kelopak mata merah & 2 \\
Mata terasa nyeri & 3 \\
Gatal pada tepi kelopak, dan & \\
mata merah & 6 \\
Ada benjolan & 9 \\
Mata merah & 9 \\
Mata tidak kabur & 9 \\
Rasa mengganjal pada mata & 7 \\
Kadang terasa gatal - gatal & 4 \\
Mata berair & 4 \\
Mata kabur perlahan & 9 \\
Mata tidak nyeri & 9 \\
Lapang pandang menyempit & 9 \\
\hline
\end{tabular}

Dari nilai probabilitas yang ditentukanoleh pakar, dapat dihitung dengan menggunakan metode Teorema Bayes, adapun contoh sudi kasus sebagai berikut:

Clarisa mengalami gejala penglihatan berkabut di matanya.Dokter menduga bahwa Clarisa terkena penyakit:
a. Katarak dengan probabilitas memandang gejala $=0.9$

b. Katarak dengan probabilitas tak memandang gejala apapun $=0.5$
c. Keratitis dengan probabilitas memandang $=0.1$

d. Keratitis dengan probabilitas tak memandang gejala apapun $=0.2$

e. Hordiolum dengan probabilitas memandang $=0.1$

f. Hordiolum dengan probabilitas tak memandang gejala apapun $=0.3$ g. Konjungtiva dengan probabilitas memandang $=0.1$

h. Konjungtiva dengan probabilitas tak memandang gejala apapun $=0.2$

i. Glukoma dengan probabilitas memandang $=0.2$

j. Glukoma dengan probabilitas tak memandang gejala apapun $=0.1$

Adapun dalam peerhitungannya dengan menggunakan Teorema Bayes sebagai berikut :

a. Probabilitas Clarisa terkena Katarak :

$P=$ Katarak $\mid$ Penglihatan berkabut

$=\frac{(0.9)(0.5)}{(0.9)(0.5)+(0.1)(0.2)+(0.1)(0.3)+(0.1)(0.2)+(0.2)(0.1)}$

$=\frac{0.45}{0.54}=0.83$

b. Probabilitas Clarisa terkena Keratitis:

$P=$ Keratitis $\mid$ Penglihatan berkabut

$=\frac{(0.1)(0.2)}{(0.9)(0.5)+(0.1)(0.2)+(0.1)(0.3)+(0.1)(0.2)+(0.2)(0.1)}$

$=\frac{0.02}{0.54}=0.037$

c. Probabilitas Clarisa terkena Hordiulum:

$P=$ Hordiolum $\mid$ Penglihatan berkabut

$\frac{(0.1)(0.3)}{(0.9)(0.5)+(0.1)(0.2)+(0.1)(0.3)+(0.1)(0.2)+(0.2)(0.1)}$
$=\frac{0.03}{0.54}=0.056$

d. Probabilitas Clarisa terkena Konjungtiva:

$\begin{aligned} & P=\text { Konjungtiva } \mid \text { Penglihatan berkabut } \\ & (0.1)(0.2)\end{aligned}$
$\begin{aligned} & (0.9)(0.5)+(0.1)(0.2)+(0.1)(0.3)+(0.1)(0.2)+(0.2)(0.1) \\ & =\frac{0.02}{0.54}=0.037\end{aligned}$

e. Probabilitas Clarisa terkena Glukoma:

$P=$ Glukoma $\mid$ Penglihatan berkabut

$\frac{(0.2)(0.1)}{(0.9)(0.5)+(0.1)(0.2)+(0.1)(0.3)+(0.1)(0.2)+(0.2)(0.1)}$ $=\frac{0.02}{0.54}=0.037$

Maka dapat disimpulkan probabilitas nilai tertinggi, Clarisa menderita penyakit Katarak dengan nilai $0.83 \%$.

Berikut ini hasil implementasi sistem pakar diagnosis penyakit mata yang terlihat pada Gambar 1 untuk tampilan menu utama, Gambar 2 untuk halaman pendaftaran, Gambar 3 untuk halaman diagnosis, dan Gambar 4 untuk halaman hasil diagnosis. 


\section{1) Tampilan Halaman Utama}

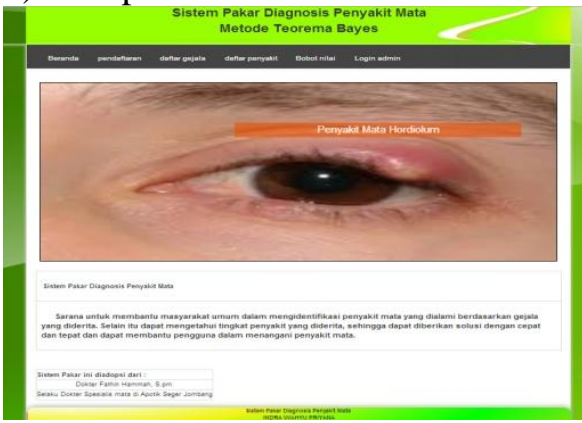

Gambar 1. Halaman utama

2) Tampilan Pendaftaran

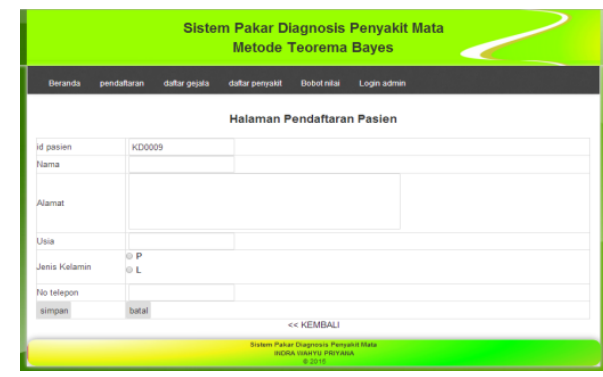

Gambar 2. Halaman Pendaftaran

3) Tampilan diagnosis

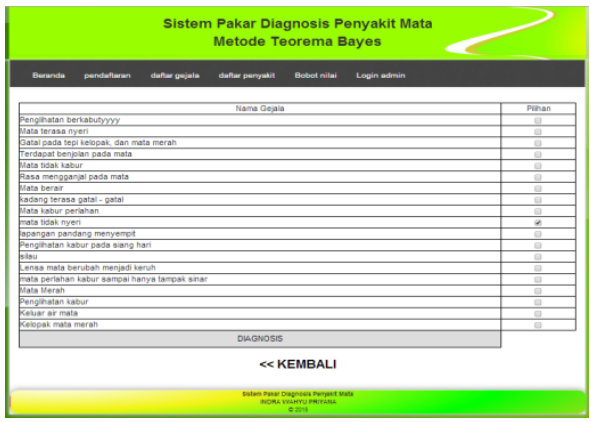

Gambar 3. Halaman diagnosis

\section{4) Tampilan Hasil Diagnosis}

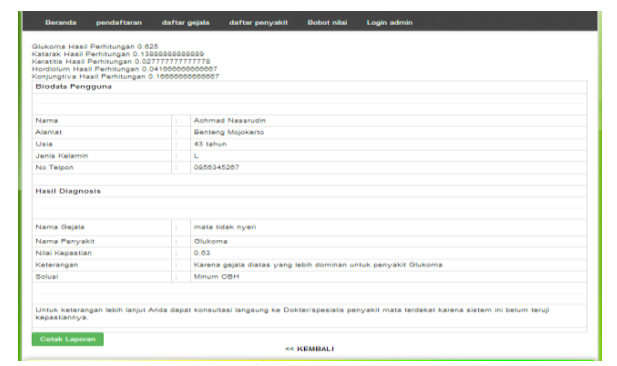

Gambar 4. Hasil Diagnosis

Pengujian sistem dilakukan dengan uji kepakaran yaitu dengan membandingkan hasil diagnosis dari sistem dengan pakar, dapat dilihat pada Tabel 6 .

Tabel 6.Tabel Perbandingan Hasil Diagnosis Sistem Pakar

\begin{tabular}{|c|c|c|c|}
\hline $\begin{array}{l}\text { No. } \\
\text { Kas } \\
\text { us }\end{array}$ & Diagnosis Pakar & Penyakit & $\begin{array}{c}\text { Nilai } \\
\text { Akur } \\
\text { asi }\end{array}$ \\
\hline 1 & Penglihatan & & \\
\hline & $\begin{array}{ll}\text { Berkabut, } & \text { Mata } \\
\text { Nyeri, } & \text { Mata } \\
\text { tidak kabur } & \end{array}$ & Katarak & 1 \\
\hline 2 & $\begin{array}{l}\text { Terdapat } \\
\text { benjolan pada } \\
\text { mata, mata } \\
\text { berair, kadang } \\
\text { terasa gatal }\end{array}$ & $\begin{array}{l}\text { Hordiolu } \\
\text { m }\end{array}$ & 1 \\
\hline 3 & $\begin{array}{l}\text { Silau, Mata } \\
\text { merah, } \\
\text { Penglihatan } \\
\text { kabur }\end{array}$ & Keratitis & 1 \\
\hline 4 & $\begin{array}{lr}\text { Mata } & \text { kabur } \\
\text { perlahan, } & \text { silau, } \\
\text { lensa } & \text { mata } \\
\text { keruh } & \end{array}$ & Glukoma & 1 \\
\hline 5 & $\begin{array}{l}\text { Mata tidak } \\
\text { kabur, rasa } \\
\text { mengganjal } \\
\text { pada mata, } \\
\text { lapang pandang } \\
\text { menyempit. }\end{array}$ & $\begin{array}{l}\text { konjungti } \\
\text { va }\end{array}$ & 0 \\
\hline 6 & $\begin{array}{l}\text { Mata tidak } \\
\text { nyeri, mata } \\
\text { merah, kelopak } \\
\text { mata merah }\end{array}$ & Glukoma & 0 \\
\hline 7 & $\begin{array}{l}\text { Mata perlahan } \\
\text { kabur sampai } \\
\text { tampak sinar, } \\
\text { penglihatan } \\
\text { berkabut, mata } \\
\text { berair }\end{array}$ & Katarak & 1 \\
\hline 8 & $\begin{array}{l}\text { Rasa } \\
\text { mengganjal } \\
\text { pada mata, } \\
\text { lapang pandang } \\
\text { menyempit, } \\
\text { silau }\end{array}$ & $\begin{array}{l}\text { Konjungt } \\
\text { iva }\end{array}$ & 1 \\
\hline 9 & $\begin{array}{l}\text { Mata merah, } \\
\text { keluar air mata, } \\
\text { kelopak mata } \\
\text { merah }\end{array}$ & Keratitis & 0 \\
\hline 10 & $\begin{array}{l}\text { Terdapat } \\
\text { benjolan pada } \\
\text { mata, silau, } \\
\text { mata merah }\end{array}$ & $\begin{array}{l}\text { Hordiolu } \\
\text { m }\end{array}$ & 1 \\
\hline 11 & $\begin{array}{lr}\text { Mata } & \text { tidak } \\
\text { nyeri, } & \text { mata } \\
\text { merah, } & \text { kelopak }\end{array}$ & Katarak & 0 \\
\hline
\end{tabular}




\begin{tabular}{|c|c|c|c|}
\hline $\begin{array}{c}\text { No. } \\
\text { Kas } \\
\text { us } \\
\end{array}$ & Diagnosis Pakar & Penyakit & $\begin{array}{c}\text { Nilai } \\
\text { Akur } \\
\text { asi }\end{array}$ \\
\hline & mata merah & & \\
\hline 12 & $\begin{array}{l}\text { Mata kabur } \\
\text { perlahan, silau, } \\
\text { lapang pandang } \\
\text { menyempit }\end{array}$ & $\begin{array}{l}\text { Hordiolu } \\
\mathrm{m}\end{array}$ & 1 \\
\hline 13 & $\begin{array}{lr}\text { Silau, } & \text { Mata } \\
\text { merah, } & \text { keluar } \\
\text { air mata } & \end{array}$ & $\begin{array}{c}\text { Konjungt } \\
\text { iva }\end{array}$ & 0 \\
\hline 14 & $\begin{array}{l}\text { Penglihatan } \\
\text { Berkabut, Mata } \\
\text { Nyeri, silau }\end{array}$ & Glukoma & 1 \\
\hline 15 & $\begin{array}{l}\text { Rasa } \\
\text { mengganjal } \\
\text { pada mata, mata } \\
\text { merah, silau }\end{array}$ & $\begin{array}{c}\text { Hordiolu } \\
\mathrm{m}\end{array}$ & 1 \\
\hline 16 & $\begin{array}{l}\text { Mata tidak } \\
\text { kabur, rasa } \\
\text { mengganjal } \\
\text { pada } \\
\text { mata,keluar air } \\
\text { mata }\end{array}$ & Katarak & 0 \\
\hline 17 & $\begin{array}{l}\text { Mata tidak } \\
\text { nyeri, silau, } \\
\text { mata merah }\end{array}$ & Keratitis & 0 \\
\hline 18 & $\begin{array}{l}\text { Keluar air mata, } \\
\text { silau, } \\
\text { pandangan } \\
\text { perlahan kabur }\end{array}$ & Keratitis & 1 \\
\hline 19 & $\begin{array}{l}\text { Lapang pandang } \\
\text { menyempit, } \\
\text { silau, keluar air } \\
\text { mata }\end{array}$ & $\begin{array}{c}\text { Konjungt } \\
\text { iva }\end{array}$ & 1 \\
\hline 20 & $\begin{array}{lr}\text { Mata } & \text { terasa } \\
\text { nyeri, } & \text { silau, } \\
\text { kelopak } & \text { mata } \\
\text { merah } & \end{array}$ & $\begin{array}{l}\text { Hordiolu } \\
\mathrm{m}\end{array}$ & 0 \\
\hline 21 & $\begin{array}{l}\text { Kelopak mata } \\
\text { merah, } \\
\text { penglihatan } \\
\text { berkabut, mata } \\
\text { berair }\end{array}$ & Keratitis & 1 \\
\hline 22 & $\begin{array}{l}\text { Mata tidak } \\
\text { kabur, } \\
\text { penglihatan } \\
\text { berkabut, mata } \\
\text { berair }\end{array}$ & Katarak & 1 \\
\hline 23 & $\begin{array}{l}\text { Mata perlahan } \\
\text { kabur sampai } \\
\text { tampak } \\
\text { sinar,mata } \\
\text { merah, silau }\end{array}$ & Glukoma & 1 \\
\hline 24 & $\begin{array}{l}\text { Mata tidak } \\
\text { nyeri, lapang } \\
\text { pandang } \\
\text { menyempit, }\end{array}$ & $\begin{array}{l}\text { Hordiolu } \\
\mathrm{m}\end{array}$ & 0 \\
\hline
\end{tabular}

\begin{tabular}{|c|c|c|c|}
\hline $\begin{array}{c}\text { No. } \\
\text { Kas } \\
\text { us }\end{array}$ & Diagnosis Pakar & Penyakit & $\begin{array}{c}\text { Nilai } \\
\text { Akur } \\
\text { asi }\end{array}$ \\
\hline 25 & $\begin{array}{l}\text { mata berair } \\
\text { Silau, } \\
\text { penglihatan } \\
\text { berkabut, lensa } \\
\text { mata keruh }\end{array}$ & $\begin{array}{l}\text { Konjungt } \\
\text { iva }\end{array}$ & 1 \\
\hline 26 & $\begin{array}{l}\text { Silau, } \\
\text { merah, lensa } \\
\text { mata keruh }\end{array}$ & Katarak & 1 \\
\hline 27 & $\begin{array}{l}\text { Silau, keluar air } \\
\text { mata, } \\
\text { Penglihatan } \\
\text { kabur }\end{array}$ & Glukoma & 0 \\
\hline 28 & $\begin{array}{l}\text { Rasa } \\
\text { mengganjal } \\
\text { pada mata, Mata } \\
\text { merah, } \\
\text { Penglihatan } \\
\text { kabur }\end{array}$ & $\begin{array}{l}\text { Hordiolu } \\
\text { m }\end{array}$ & 1 \\
\hline 29 & $\begin{array}{l}\text { Silau, mata } \\
\text { nyeri, } \\
\text { Penglihatan } \\
\text { kabur }\end{array}$ & $\begin{array}{l}\text { Konjungt } \\
\text { iva }\end{array}$ & 1 \\
\hline 30 & $\begin{array}{l}\text { Silau, terdapat } \\
\text { benjolan, mata } \\
\text { merah }\end{array}$ & $\begin{array}{l}\text { Hordiolu } \\
\text { m }\end{array}$ & 1 \\
\hline & Jumlah & & 20 \\
\hline
\end{tabular}

Jika dihitung probabilitasnya :

Nilai akurasi $=\mathrm{\imath} 100 \% \underline{\text { Jumlah data }}$ akuratJumlah seluruh

$$
\begin{aligned}
& =\frac{20}{30} \times 100 \% \\
& =63,3 \%
\end{aligned}
$$

Selain itu terdapat kategori penilaian sistem yang terlihat pada Tabel 7 . 
Tabel 7. Tabel kategori prosentase penilaian sistem

\begin{tabular}{|c|c|c|c|c|}
\hline \multicolumn{5}{|c|}{ Kategori (\%) } \\
\hline $\begin{array}{c}\text { Tidak } \\
\text { Baik }\end{array}$ & $\begin{array}{c}\text { Kurang } \\
\text { Baik }\end{array}$ & $\begin{array}{c}\text { Cukup } \\
\text { Baik }\end{array}$ & Baik & $\begin{array}{l}\text { Sangat } \\
\text { Baik }\end{array}$ \\
\hline $0-20$ & $21-40$ & $41-60$ & $61-80$ & $81-100$ \\
\hline
\end{tabular}

menunjukan hasil dari uji kepakarannya mendapat keakuratan $63,3 \%$ jadi sistem masuk dalam kategori baik untuk digunakan,

\section{Kesimpulan dan Saran}

Berdasarkan hasil pembahasan yang telah dilakukan sebelumnya, maka dapat ditarik kesimpulan bahwa:

1. Sistem pakar ini dirancang dengan menggunakan metode waterfall, dan dibangun dengan menggunakan bahasa pemrograman PHP dan $M y S q l$ versi 5.5.1.

2. Sistem pakar ini menggunakan metodeTeorema Bayesdalam mendiagnosis penyakit mata, yang dapat memberikan hasil diagnosis dengan cepat beserta tingkat kepastian setiap penyakit.

3. Dari hasil perhitungan diagnosis yang dilakukan oleh sistem dapat diketahui titik keakuratan diagnosis sistem dengan dokter mencapai $63,3 \%$.

Dari kesimpulan yang ada dapat diketahui bahwa penelitian yang dilakukan masih terdapat kekurangan. Oleh karena itu, diperlukan saran untuk kebaikan pengembangan sistem lebih lanjut, diantaranya

1. Penambahan solusi, karena solusi ini tidak bersifat mutlak.

2. Penambahan uji kelayakan sistem karena sistem ini belum teruji kebenarannya dengan beberapa pendapat pakar atau banyaknya pasien.
3. Tampilan sistem pakar yang dibangun masih tampak sederhana, sehingga dapat dikembangkan lebih baik dan lebih menarik seperti dirancang kesebuah aplikasi mobile.

4. Penambahan metode lain untuk mengatasi kesulitan kepastian data dalam diagnosis, dikarenakan metode Teorema Bayes hanya menentukan probabilitas dari suatu gejala penyakit mata yang ditimbulkan.

\section{Daftar Pustaka}

InfoDatin.(2014). Situasi Gangguan Penglihatan Dan Kebutaan.Jakarta Selatan: Kementrian Kesehatan RI Tersedia :http://www.depkes.go.id/folder/view/01 /structure-publikasi-pusdatin-infodatin.html.

Arhami, M. (2005).Konsep Dasar Sistem Pakar. Yogyakarta: ANDI.

Ongko, Erianto. (2013). Perancangan Sistem Pakar Diagnosa Penyakit Mata.Jurnal Times(JTM),vol.II, no.2, hal.10-17.

Marlisa, Ririn (2014). Sistem Pakar Mendiagnosa Keguguran Pada Ibu Hamil Berdasarkan Jenis Makanan Dengan Metode Teorema Bayes.Informasi dan Teknologi Ilmiah (INTI), vol.IV, no3, hal.24-32. 